\title{
Influence of Value analysis and Cross Training in Industry
}

\author{
S.Vasanthi, S.Rabiyathul Basariya
}

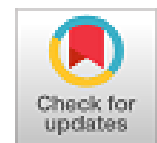

\begin{abstract}
Cross training makes the employees to learn different skills. Employer can utilize the new skills of the employees at the time of crisis like during the absenteeism of key employees, leave taken by employees during critical times etc. Employees will also understand the needs of the organisation and helps to fulfil them by handling different tasks. This paper defines what is value analysis, cross training and benefits of value analysis of cross training.
\end{abstract}

Keywords: Value analysis, cross training, benefits of cross training, benefits of value analysis.

\section{INTRODUCTION:}

An employee learning to do different tasks within his domain is called as cross training. He will become well rounded professionally by undergoing the cross training. Employee A will get to learn the tasks that are being done by employee $\mathrm{B}$. In case of absence or long leave of $\mathrm{B}$, the tasks of $\mathrm{B}$ will be done by A to have the continuity of the work. It can be implemented at any level in an organisation, either at technician level or for managers.

Value analysis is defined as analyzing the cost of the process and modifying the design to optimize the costs. Identifying unnecessary expenses and avoiding them, improving the quality of product at the no additional costs is part of value analysis.

\section{OBJECTIVES:}

- Defining Cross training

- Defining Value analysis

- $\quad$ Explaining the benefits of value analysis and cross training in industry

\section{REVIEW OF LITERATURE}

According to Jerry Osteryoung, a professor of entrepreneurship at Florida University, cross-training is the systematic process to train workers to perform their colleagues' jobs. To perform it effectively, it must be done both vertically and horizontally throughout the organization. Managers need to cross-train into jobs of other managers, as well as into lower-level jobs. Campion, Cheraskin and Michael (1994) defines job rotations as lateral transfers of employees between jobs in an organization". This is nothing but the cross training.

Revised Manuscript Received on October 30, 2019.

* Correspondence Author

S.Vasanthi, Research Scholar, Bharath Institute of Higher Education and Research, Chennai.

Dr.S.Rabiyathul Basariya, Associate Professor \& Research Supervisor, Dept of Commerce \& Business Administration, Bharath Institute of Higher Education and Research, Chennai.

(C) The Authors. Published by Blue Eyes Intelligence Engineering and Sciences Publication (BEIESP). This is an open access article under the CC BY-NC-ND license (http://creativecommons.org/licenses/by-nc-nd/4.0/)
According to Rui Ming Jie (2005), the knowledge updating in a firm contains three aspects: individual learning, knowledge from outside resources and reciprocal action between employees. So it is reasonable to analyze the value of job rotation on human capital development on the base of Rui Ming Jie's viewpoint.

Foot and Hook, 1996 confirms that when training is not evaluated, the investment and its effects cannot be tested and resources can be wasted in inadequate activities. Sometimes, training evaluation is avoided because it is considered an expensive and time-consuming process (Buckley and Caple, 1991; Go'mez-Mej1'a et al., 1996). Wexley \& Latham(1991) confirms that the training programs which fulfils the employee and organizational goals and needs and matches the business strategy will achieve great success. Employees shall be trained based on the evaluation results of their output.

The success of training depends on the correct implementation of all steps of the process: previous analysis of training needs, development and implementation of an adequate training plan and evaluation.

\section{CROSS TRAINING}

Employee productivity is directly proportionate to the skills he has developed. That means the more training given to an employee will improve the productivity of the organisation. Any employee at any position can be trained for other skills after analyzing the interests of the employee and benefits of the training. For example, an organisation who has high rate of customer contact will cross train their customer support representatives on the performance of different products. Technology based companies will cross train their employees to learn different technologies they are using in their organisation. Employees who shows interest in learning new skills and invest their time will be chosen for cross training.

Planning for cross training should have the objects of both employee benefits and employer benefits. It should not be one sided or hasty decision. If not planned well, it will just consume the time and money of both employee and employer.

\section{Benefits of cross training:}

Cross training an employee will make him feel empowered and more knowledgeable. This will increase his self confidence and he can produce the qualitative work. There are a bundle of benefits, among which few are given below:

- Employee will become aware of all the roles and functions of the organisation

- Flexibility will be there in assigning and planning of work

- Employee will have more job opportunities in case he wants to look for a new job.

- Employee absenteeism and turnover will not affect the production much. 
- Job enlargement which is the horizontal expansion can be easily achievable by implementing cross training

- Members who are providing training will expand their knowledge as they are constantly engaged in training activities

- It reduces the cost of recruiting new employees

- Team work among the employees will be improved

- Makes the employees to get recognized and rewarded.

- Trainees who has undergone cross training will become experts in that skill.

- An environment of continuous learning will be created in the organisation where cross training is implemented.

- Enables the employer to create a flexible work force.

- Employees are exposed to learn good practices and new ideas

In a nut shell, cross training improves employee knowledge and job satisfaction. Overall performance and production of the organisation will also be increased.

\section{VALUE ANALYSIS}

Value analysis is defined as a process of examining and organizing the processes and costs that goes into manufacturing in an organisation. All the factors that contribute to the overall cost of the product will be examined systematically in order the optimize the expenses and cost reduction without compromising the quality and performance of the product. It is critical examination or study of the design, development and functions of a product related to the costs in order to bring down the costs. Management uses the value analysis as a tool to save the costs. It is a systematic analysis of production techniques and functions of different departments and aims to eliminate the unnecessary costs. These costs may be incurred in the production process or in the quality improvement process or for the human resources. By eliminating all these avoidable costs, overall cost of the production will come down, good quality product can be produced and costs on the human resources can be optimized.

Value analysis is to be done with the following requirements.

- To eliminate the wastages in the production

- To use alternate materials

- To reduce labour cost

- To maintain the quality

- To utilize the skills of the employees

- To define and utilize the alternate and cost effective operations

Benefits of Value Analysis:

- $\quad$ Reduces the product cost

- Usage of good quality raw materials

- Optimizes the production process

- Increase the overall profit

- $\quad$ Stages of Value analysis

- Needs and requirements of customers are to be recognized

- Defining the work for the production

- Simplification and standardization of the work

- Relating the performance and work

- $\quad$ Preparing the employees for maximum production

- Innovation and creativity will be promoted which will help to develop new ideas.

- Efficiency in the production will be increased

\section{RELATING VALUE ANALYSIS AND CROSS TRAINING}

Cross training the employees and implementing value analysis in the company will bring lots of benefits. It will help to standardize the production process and reduces the production costs. Cross trained employees can understand the entire processes in the company and helps for costreduction. As the employees are cross trained, a good communication and friendly interaction will be developed among them. This type of relation between the employees will be helpful to achieve higher efficiency.

\section{CONCLUSION}

Training given to employees needs to be evaluated and the production process also to be evaluated. One of the efficient methods of training the employees is cross train them. Evaluating the cross training and evaluating is interrelated. Both the methods aims at reducing the costs to the company and producing the high quality products by utilizing the cost effective techniques with minimal human resources. Implementing the value analysis and cross training in an industry will bring the benefits like measuring the effectiveness of the human resources as well as the production process in the organisation.

\section{REFERENCES}

1. Campion, M. A., Cheraskin, L. S., \& Michael, J. (1994, December) Career-related antecedents and outcomes of job rotation. Academy of Management Journal, v 37, (6),

2. Foot, M. and Hook, C. (1996) Introducing Human Resource Management. Singapore: Longman.

3. Baldwin T. T. \& Ford J. K., "Transfer of training: A review and directions for future research", Personnel Psychology, 1988, 63-105

4. Wexley K. N. \& Latham G. P., "Developing and training human resources in organizations (2nd ed.)", New York: HarperCollins, 1991

5. https://pdfs.semanticscholar.org/b4bd/d086e7aff63a1fe3bbf4e80533c $\underline{6975 f 225 c . p d f}$ 